\title{
Structural and optical properties of $\mathrm{VO}^{2+}$ doped methacrylic acid ethylacrylate (MAA:EA) copolymer films
}

\author{
Y. Madhava Kumar, K. Bhyagyasree, N.O. Gopal, Ch. Ramu* \\ Department of Physics, Vikrama Simhapuri University PG Centre, Kavali 524201, India.
}

\begin{abstract}
Pure and $\mathrm{VO}^{2+}$ doped methacrylic acid ethylacrylate (MAA:EA) copolymer films were prepared by using a solution casting method. Various techniques including X-ray diffraction, Fourier transform infrared spectroscopy, ultraviolet-visible spectroscopy, scanning electron microscopy and electron paramagnetic resonance were employed for characterization of the samples. XRD patterns showed some degree of crystallinity of the doped polymer films due to interaction of the MAA:EA copolymer with $\mathrm{VO}^{2+}$. FT-IR spectral studies of pure and $\mathrm{VO}^{2+}$ doped MAA:EA copolymer films displayed significant structural changes within the doped copolymer film indicating the complexation. The optical absorbance of the pure and $\mathrm{VO}^{2+}$ doped films were measured in the $200 \mathrm{~nm}$ to $800 \mathrm{~nm}$ wavelength range. The values of the absorption edge and indirect band gaps were calculated. The optical band gap decreased with the increase of mol\% of $\mathrm{VO}^{2+}$. From the EPR spectra, the spinHamiltonian parameters ( $\mathrm{g}$ and $\mathrm{A}$ ) were evaluated. The values of the spin-Hamiltonian parameters confirmed that the vanadyl ions were present in MAA:EA copolymer films as $\mathrm{VO}^{2+}$ molecular ions in an octahedral site with a tetragonal compression $\left(\mathrm{C}_{4 \mathrm{v}}\right)$. The morphology of the copolymer samples was examined by scanning electron microscopy. The enhanced crystalline nature of the doped copolymer was identified from SEM analysis.
\end{abstract}

Keywords: absorption edge; direct band gap; indirect band gap; methacrylic acid ethylcrylate; electron paramagnetic resonance

\section{Introduction}

Copolymers are hybrid macromolecules that have attracted the attention of scientists and technologists over the last several decades. Copolymer films are used in a number of technological and scientific applications due to their optical, thermal, mechanical, electronic and electrical properties. In recent years, there has been a considerable interest in the preparation and characterization of copolymer films for their possible use as light stable color filters [1] as well as solar cells and optical sensors [2]. If the properties of a copolymer are tuned in the right direction by adding suitable dopants, this copolymer could be an appropriate candidate for space applications [3].

The interaction of a copolymer with oppositely charged dopants has been extensively studied because of its complex behavior. The interaction between an oppositely charged polymer and dopant

*E-mail: chramu8@gmail.com is usually strong because of Coulombic attractive forces. The binding is generally considered as an electrostatic binding via ion exchange interaction. Typically, the electrostatic interaction is reinforced by dopant or the cooperative aggregation between alkyl chains of the dopant and hydrophobic segments of the copolymer chains $[4,5]$. On the other hand, the complexation of a copolymer with a weak cationic dopant, such as partially neutralized or unneutralized polycarboxylic acid, has also been extensively studied. Because of the industrial applications $[6,7]$, this system has a potential utility in the control of chemical reactivity, drug delivery and nano-specific binding of DNA [8].

Methacrylic acid-ethyl acrylate (MAA:EA) copolymer has drawn a special attention amongst the copolymers because of its good environmental stability, easy processing and transparency. MAA:EA has good charge capacity and dopant dependent electrical and optical properties. The chemical structure of MAA:EA copolymer is shown in Fig. 1. 


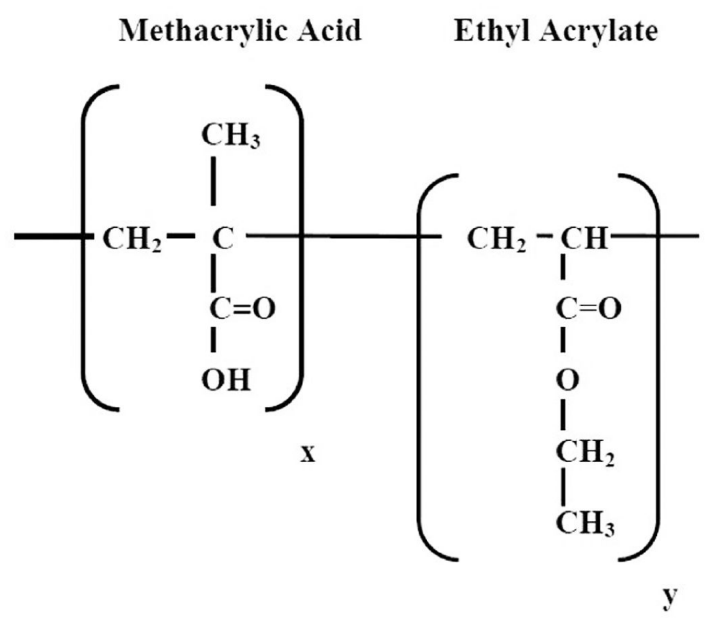

Fig. 1. Chemical structure of MAA:EA copolymer.

There are many methods to improve the ionic conductivity, optical properties, mechanical and electrical properties of polymer films, viz. polymer blending, addition of plasticizer, doping of ionic liquid, filler and mixed salt systems. Bajaj et al. [9] studied the thermal behavior of MAA:EA copolymers. They also showed that methanol and ethanol degraded below $280{ }^{\circ} \mathrm{C}$, whereas $\mathrm{CO}_{2}, \mathrm{CO}$ and olefin degraded at $400{ }^{\circ} \mathrm{C}$. Wang et al. [4] studied the interaction between MAA:EA copolymer and bromide dopant. They reported that addition of salt to MAA:EA copolymer weakened the binding of surfactant onto the polymers favoring the formation of free micelles.

Among the transition metal ions, $\mathrm{VO}^{2+}$ has been extensively used as a probe to study the symmetry of crystalline electric field [10]. Vanadium oxides have also shown promise as optical switching materials due to their electro-chromic properties [11-14]. The properties of the $\mathrm{VO}^{2+}$ doped MAA:EA copolymer films are reported in this paper.

\section{Experimental}

Methacrylic acid-ethyl acrylate copolymer (1:1) 30 percent dispersion with molecular weight of 250,000 was purchased from Merck Millipore India Ltd. MAA:EA copolymer films $(14 \mu \mathrm{m}$ thickness) doped with $\mathrm{VO}^{2+}$ at various concentrations were prepared at room temperature by a solution casting method. The desired concentrations of $\mathrm{VOSO}_{4}$ solution $(1.5 \mathrm{~mol} \%$, $3.5 \mathrm{~mol} \%, 5 \mathrm{~mol} \%, 7.5 \mathrm{~mol} \%$ and $10 \mathrm{~mol} \%)$ were prepared by using distilled water. $5 \mathrm{~mL}$ of MAA:EA copolymer was dissolved in distilled water separately. Different amounts of $(1.5 \mathrm{~mol} \%$, $3.5 \mathrm{~mol} \%, 5 \mathrm{~mol} \%, 7.5 \mathrm{~mol} \%$ and $10 \mathrm{~mol} \%$ ) $\mathrm{VO}^{2+}$ were added into the copolymer solution. The solution was magnetically stirred for $10 \mathrm{~h}$ to $12 \mathrm{~h}$ to obtain homogeneous mixture and then cast into plastic dishes. The film was slowly evaporated at room temperature to obtain free standing copolymer films at the bottom of the dishes.

$\mathrm{X}$-ray diffraction measurements were carried out using a Siemens D5000 diffractometer with $\mathrm{CuK} \alpha$ radiation $(1.5406 \AA)$. The films were scanned at $2 \theta$ angles between $10^{\circ}$ and $80^{\circ}$ with a step size of $0.02^{\circ}$. FT-IR spectra of these films were recorded using a Perkin-Elmer FT-IR spectrometer and the spectra were taken over a wavenumber range of $400 \mathrm{~cm}^{-1}$ to $3500 \mathrm{~cm}^{-1}$. EPR spectra were recorded at room temperature on a FEIX ESR spectrometer (Japan Electro Optics Ltd.) operating in $\mathrm{X}$-band frequency of $9.205 \mathrm{GHz}$ with field modulation of $100 \mathrm{kHz}$. The magnetic field was scanned from 0 to $5000 \mathrm{G}$. UV-Vis absorption spectra of the prepared samples were recorded in the range of $200 \mathrm{~nm}$ to $800 \mathrm{~nm}$ at room temperature using JASCO UV-Vis-NIR spectrophotometer (model V.700). From these data, the optical constants, such as band edge and indirect band gap, were determined. The thickness of the film was determined by using a computer controlled capacitance measurements at (PSM $17001 \mathrm{~Hz}$ to $1 \mathrm{MHz}$ ) using an LCR bridge, taking the dielectric constant $\epsilon$ of MAA:EA copolymer as 2.8 [15]. The morphology of the copolymer films was characterized by the JEOL JSM 840A electron microscope with a scanning attachment.

\section{Results and discussion}

\subsection{X-ray diffraction analysis}

X-ray diffraction analysis is a powerful tool for determining the structure and crystallinity 


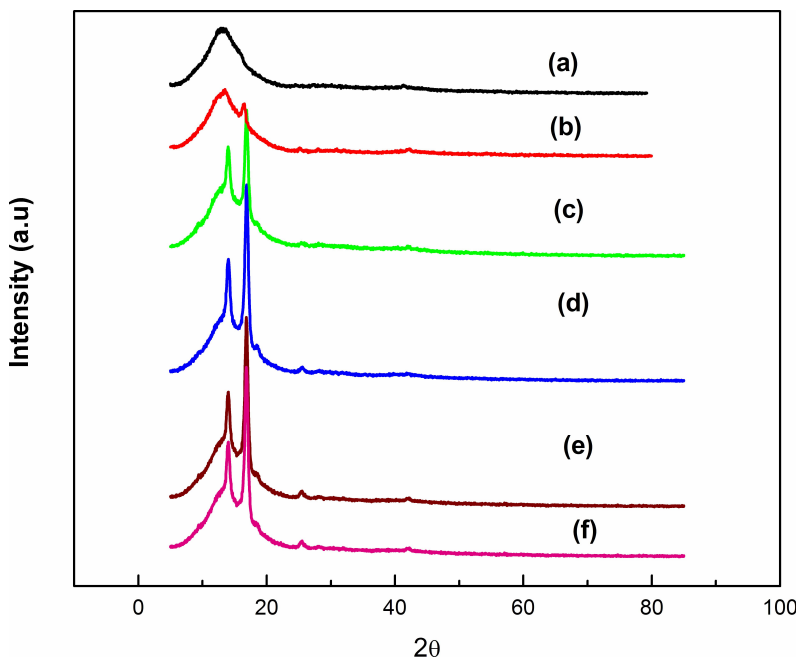

Fig. 2. XRD spectra of MAA:EA copolymer films containing $\mathrm{VO}^{2+}$ (a) pure, (b) $1.5 \mathrm{~mol} \%$, (c) $3.5 \mathrm{~mol} \%$, (d) $5 \mathrm{~mol} \%$, (e) $7.5 \mathrm{~mol} \%$, (f) $10 \mathrm{~mol} \%$.

of polymer films. The X-ray diffraction patterns of pure and $\mathrm{VO}^{2+}$ doped MAA:EA copolymer films at different concentrations $(1.5 \mathrm{~mol} \%, 3.5 \mathrm{~mol} \%$, $5 \mathrm{~mol} \%, 7.5 \mathrm{~mol} \%$ and $10 \mathrm{~mol} \%$ ) are shown in Fig. 2. The XRD pattern (Fig. 2a) of pure MAA:EA reveals an intense hump near at $11^{\circ}$ to $15^{\circ}$, clearly indicating the amorphous nature of the copolymer. $\mathrm{X}$-ray scans reveal a change in peak intensity without any significant change in the halo position accompanying the increase in the dopant concentration. Fig. 2b to Fig. 2e shows a well-defined sharp peak which indicates crystalline nature of the $\mathrm{VO}^{2+}$. On the other hand, the spectra of MAA:EA films containing $\mathrm{VO}^{2+}$ show small sharp peaks at $2 \theta=13^{\circ}$ and $16.5^{\circ}$ and intensity increasing with an increase of $\mathrm{VO}^{2+}$ content. This result indicates that the addition of dopant can cause structural variations in the polymeric network [16]. Thus, $\mathrm{VO}^{2+}$ dopant interacts well with MAA:EA; sharpness of the peaks also shows an increase in the crystallinity of the composites [17, 18]. Hodge et al. [19] established a correlation between the intensity of a peak and a degree of crystallinity. They observed that the intensity of diffraction patterns increases as the crystalline nature increases. These observations confirm that the present polymer possess both crystalline and amorphous regions.

\subsection{Fourier transform infrared spec- troscopy}

FT-IR spectroscopy plays an important role in the investigation of polymer structure as it provides information about the complexation and interactions between various constituents in a polymer film. These interactions can induce changes in the vibrational modes of the molecules in the polymer film. The FT-IR spectra of pure and $\mathrm{VO}^{2+}$ (1.5 mol\%, $3.5 \mathrm{~mol} \%, 5 \mathrm{~mol} \%, 7.5 \mathrm{~mol} \%$ and $10 \mathrm{~mol} \%$ ) doped MAA:EA copolymer films are shown in Fig. 3. The spectra exhibit bands, characteristic of stretching, bending vibrations of $\mathrm{O}=\mathrm{H}$, $\mathrm{C}=\mathrm{H}, \mathrm{C}=\mathrm{O}, \mathrm{CH}_{3}=\mathrm{O}$ and $\mathrm{CH}_{2}+\alpha=\mathrm{CH}_{3}$ graphs. In the pure film, the strong band observed at $2184 \mathrm{~cm}^{-1}$, could be assigned to $\mathrm{O}=\mathrm{H}$ stretching vibrations of hydroxyl groups of MAA:EA copolymer. The spectrum for pure MAA:EA shows a strong broad absorbance at $2184 \mathrm{~cm}^{-1}$. This band could be assigned to $\mathrm{O}=\mathrm{H}$ stretching vibrations of hydroxyl groups of MAA:EA [20]. Absorbance at $1524 \mathrm{~cm}^{-1}$ corresponds to an acetyl $\mathrm{C}=\mathrm{O}$ group, which could be explained on the basis of intermolecular hydrogen bonding with the adjacent $\mathrm{OH}$ group. The band at $691 \mathrm{~cm}^{-1}$ corresponds to $\mathrm{C}=\mathrm{O}$ stretching of acetyl group present on the MAA:EA backbone that remains the same for all the doped and undoped samples [21].

Compared to the pure film, the $\mathrm{VO}^{2+}$ doped films do not exhibit any change in their band positions, whereas the intensity of the bands varies considerably with varying $\mathrm{VO}^{2+}$ concentration. The positions of the bands have not changed but the intensity decreased at $1.5 \mathrm{~mol} \%$. This may be due to the breaking of bands in the complex. For increased dopant concentration the intensity of the peaks is also increased [22]. The increased intensity of the band indicates that greater amount of $\mathrm{VO}^{2+}$ have complexed with the oxygen and hydrogen atoms. When all the sites are fully saturated with $\mathrm{VO}^{2+}$ dopant, then the copolymer and $\mathrm{VO}^{2+}$ interaction increases which is responsible for the increasing the peak intensities. The intensity of the band corresponding to $\mathrm{C}=\mathrm{O}$ stretching of carboxylic acid observed at $1524 \mathrm{~cm}^{-1}$ has 
increased with increasing $\mathrm{VO}^{2+}$ content. The effect of dopant on the modes of vibration is observed in terms of increase in the intensity of the bands and appearance of new bands, which results from the formation of crosslinks between the $\mathrm{VO}^{2+}$ cations and oxygen atoms of carbonyl groups. This indicates the increase in the basicity of $\mathrm{C}=\mathrm{O}$ groups with an increase in $\mathrm{VO}^{2+}$ concentration. With further increase in the dopant concentration, the intensity of this band decreases at $10 \mathrm{~mol} \%$, which could be attributed to ionic association through redissociation of charge accompanying the formation of ionic pairs and aggregates. All these changes in FT-IR spectra are the indication of the complexation of MAA:EA copolymer with $\mathrm{VO}^{2+}$ and from the observed results, it is clear that $7.5 \mathrm{~mol} \%$ is the optimal doping concentration.

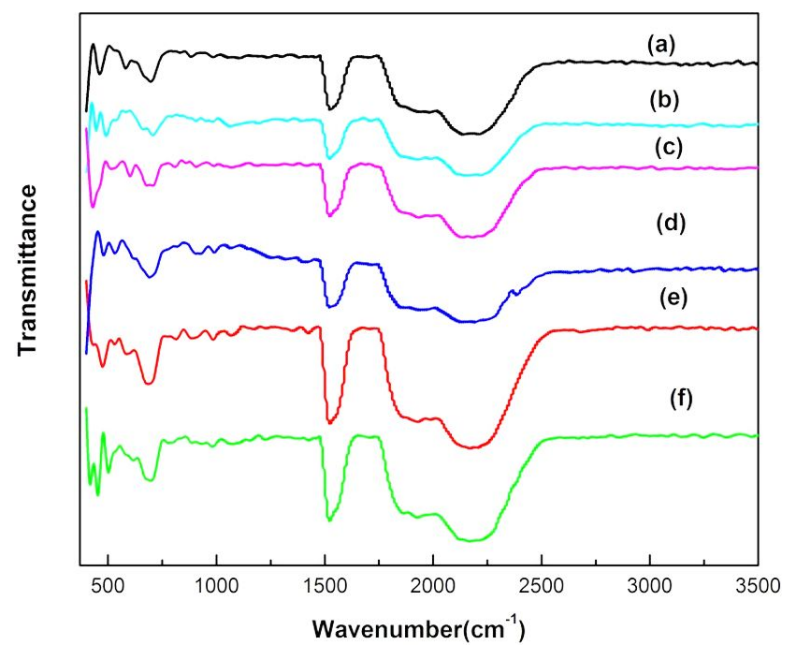

Fig. 3. FT-IR spectra of MAA:EA copolymer films containing $\mathrm{VO}^{2+}$ (a) pure, (b) $1.5 \mathrm{~mol} \%$, (c) $3.5 \mathrm{~mol} \%$, (d) $5 \mathrm{~mol} \%$, (e) $7.5 \mathrm{~mol} \%$, (f) $10 \mathrm{~mol} \%$.

\subsection{Optical studies}

UV-Vis absorption spectroscopy is a technique wherein the absorption of electromagnetic wave is measured as a function of frequency or wavelength. The absorption process induces an interaction between $\mathrm{VO}^{2+}$ and the copolymer, which can be understood through variations in the absorption spectra. An absorption spectrum is a fingerprint of a molecule or polymer material. UV-Vis absorption is a commonly used analytical tool for studying the interactions between electrons and radiation.

UV-Vis absorptions of pure and $\mathrm{VO}^{2+}$ doped copolymer films are shown in the Fig. 4. The maximum absorption for all the samples is in the range of $200 \mathrm{~nm}$ to $800 \mathrm{~nm}$. According to the graph, doping of $\mathrm{VO}^{2+}$ in MAA:EA introduced a new absorption peak at $284 \mathrm{~nm}$ in addition to the peak at $221 \mathrm{~nm}$, characteristic of pure MAA: EA copolymer. This new peak may be due to interaction of dopant and copolymer attributed to the formation of a charge transfer complex [23]. The amount of absorbance at each peak position increased with dopant concentration, the decrement in absorption edge is the result of the decreased band gap which improves the samples semiconducting behavior.

The absorption coefficient $\alpha$ can be directly determined from the spectra by:

$$
\alpha=\left(\frac{A}{d}\right) \cdot 2.303
$$

where $\mathrm{A}$ is the absorbance and $\mathrm{d}$ is the thickness of the film. The variation in the absorption coefficient with incident photon energy for undoped as well as doped MAA:EA copolymer (Fig. 5) shows that the absorption edge for undoped MAA:EA lies at $4.97 \mathrm{eV}$ while for the doped films, the values were found to decrease from $4.88 \mathrm{eV}$ to $4.55 \mathrm{eV}$ (Table 1).

When an indirect band gap exists, the absorption coefficient has the following dependence on the energy of the incident photon $[24,25]$ :

$$
\alpha=\frac{c\left(h v-E_{g}\right)^{m}}{h v}
$$

where $E_{g}$ is the optical band gap, $\mathrm{c}$ is band tailing parameter related to a constant. At the fundamental edge of semiconductor materials, two types of optical transitions can take place. In both types of optical transitions, the photon interacts with the electron in the valence band and rises it to the conduction band. There is no interaction with lattice in the direct transition, and the photon interacts with lattice in indirect transition. In the given equation $\mathrm{m}$ decides the transition: for $\mathrm{m}=1 / 2$ 
the transition is direct allowed while $\mathrm{m}=2$ for indirect allowed transition. After applying all values of $\mathrm{m}$ for the samples, $\mathrm{m}=2$ (indirect transition) is found most suitable to calculate the band gap.

The indirect band gaps were obtained from the plots of $(\alpha h v)^{1 / 2}$ vs. hv (Fig. 6). For pure (MAA:EA) copolymer film, the indirect band gap lies at $4.85 \mathrm{eV}$, while for doped films the values vary from $4.73 \mathrm{eV}$ to $4.19 \mathrm{eV}$ (Table 1).

From Table 1, it is clear that the band edge and indirect band gap values show a decrease with an increase of dopants. The decrease in optical band gap on doping may be explained on the basis of the fact that incorporation of small amount of dopants forms charge transfer complexes in the host lattice. The band edge and indirect band gap values shifting to lower energies on doping with $\mathrm{VO}^{2+}$ is due to interband transitions [26].

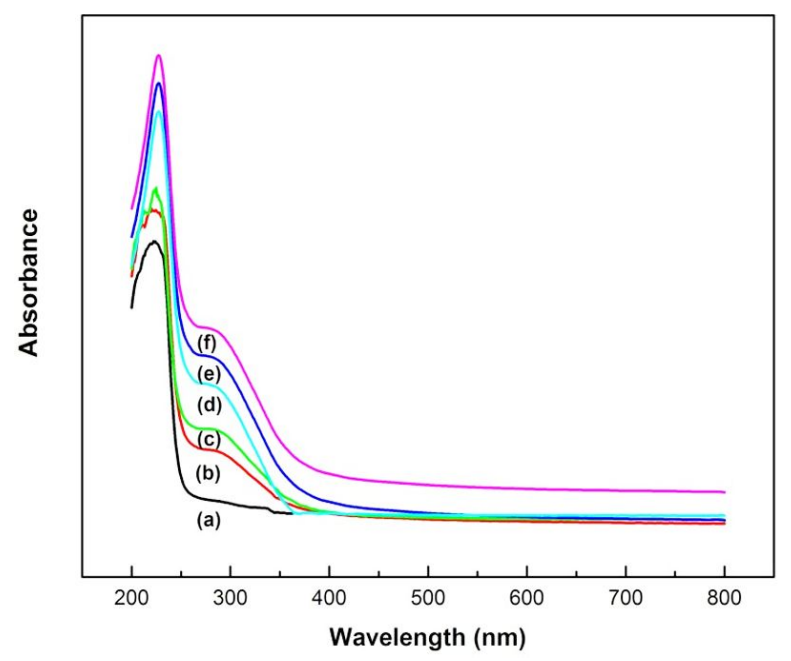

Fig. 4. Ultraviolet absorption spectra for MAA: MAA: EA copolymer films containing $\mathrm{VO}^{2+}$ (a) pure, (b) $1.5 \mathrm{~mol} \%$, (c) $3.5 \mathrm{~mol} \%$, (d) $5 \mathrm{~mol} \%$, (e) $7.5 \mathrm{~mol} \%$, (f) $10 \mathrm{~mol} \%$.

\subsection{Electron paramagnetic resonance studies}

No EPR signal was observed in the spectra of undoped MAA:EA copolymer film indicating that no paramagnetic impurities were present in the starting materials. When various amounts of $\mathrm{VO}^{2+}$ were added to MAA:EA copolymer, the EPR

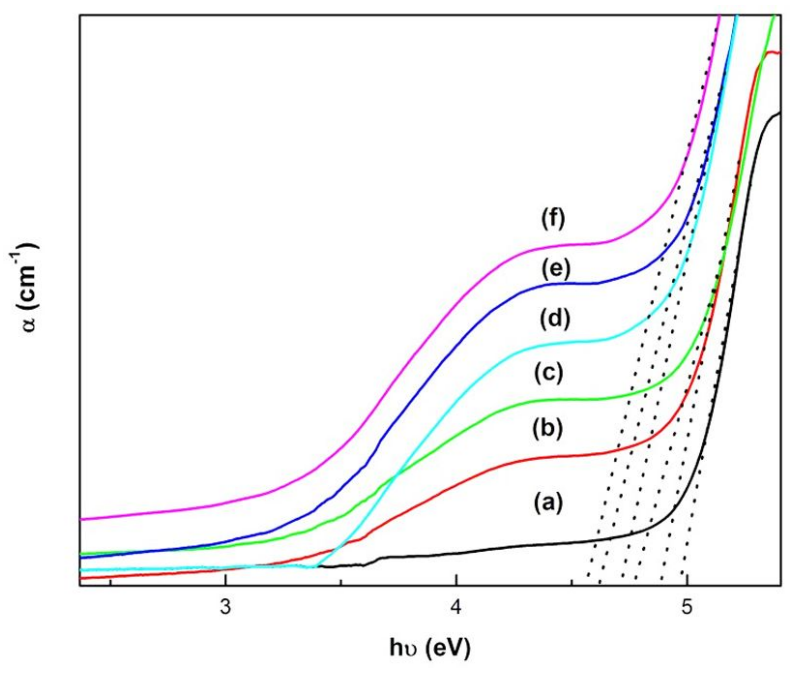

Fig. 5. $\alpha$ vs hv plots of MAA: EA copolymer films containing $\mathrm{VO}^{2+}$ (a) pure, (b) $1.5 \mathrm{~mol} \%$, (c) $3.5 \mathrm{~mol} \%$, (d) $5 \mathrm{~mol} \%$, (e) $7.5 \mathrm{~mol} \%$, (f) $10 \mathrm{~mol} \%$.

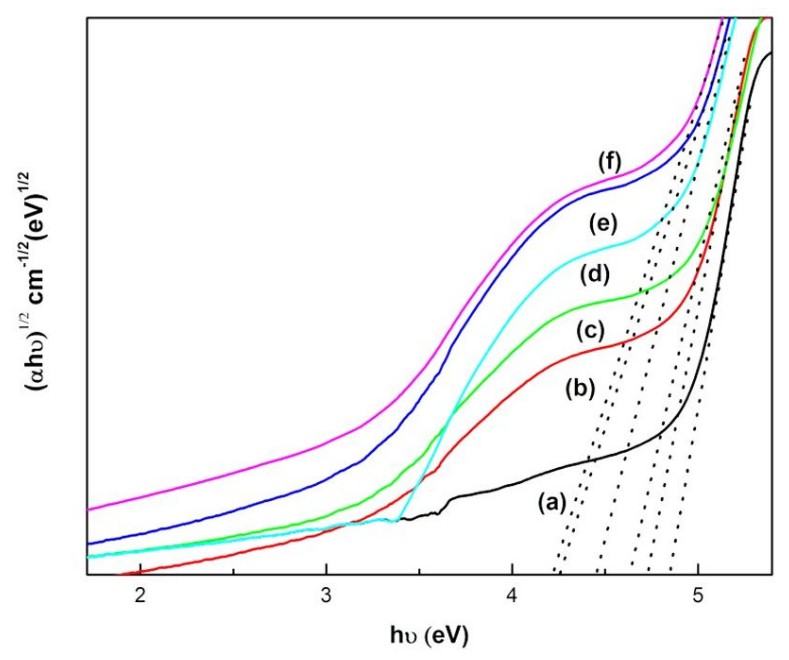

Fig. 6. $(\alpha h v)^{1 / 2}$ vs hv plots of MAA:EA copolymer films containing $\mathrm{VO}^{2+}$ (a) pure, (b) $1.5 \mathrm{~mol} \%$, (c) $3.5 \mathrm{~mol} \%$, (d) $5 \mathrm{~mol} \%$, (e) $7.5 \mathrm{~mol} \%$, (f) $10 \mathrm{~mol} \%$.

spectra of all the investigated samples exhibited resonance signal as shown in Fig. 7. Generally, the coordination of vanadium is octahedral with tetragonal distortions [27]. The observed resonance signals are due to the hyperfine interaction of an unpaired electron $(S=1 / 2)$ with a ${ }^{51} \mathrm{~V}$ nucleus whose nuclear spin is $7 / 2$ and which is present in abundance $(99.76 \%)$. An octahedral site symmetry 
Table 1. Absorption edge and indirect band gap values of pure and $\mathrm{VO}^{2+}$ doped (MAA:EA) copolymer films.

\begin{tabular}{ccc}
\hline $\begin{array}{c}\text { Concentration mol\% } \\
\mathrm{VO}^{2+} \text { :MAA:EA }\end{array}$ & $\begin{array}{c}\text { Absorption edge } \\
{[\mathrm{eV}]}\end{array}$ & $\begin{array}{c}\text { Indirect band gap energy } \\
{[\mathrm{eV}]}\end{array}$ \\
\hline \hline Pure MAA:EA & 4.97 & 4.85 \\
1.5 & 4.88 & 4.73 \\
3.5 & 4.80 & 4.67 \\
5 & 4.71 & 4.47 \\
7.5 & 4.65 & 4.33 \\
10 & 4.55 & 4.19 \\
\hline
\end{tabular}

with a tetragonal compression would give values of $\mathrm{g}_{\|}<\mathrm{g}_{\perp}<\mathrm{g}_{\mathrm{e}}(=2.0023)$ and $\mathrm{A}_{\|}>\mathrm{A}_{\perp}$ [28]. The present values of the spin-Hamiltonian parameters agree with the above condition. From this observation, it is suggested that the paramagnetic $\mathrm{V}^{4+}$ ions in the framework exist as vanadyl ions, $\mathrm{VO}^{2+}$ in the octahedral environment of oxygen with tetragonal distortion. The evaluated spin-Hamiltonian parameters are presented in Table 2. When the concentration of $\mathrm{VO}^{2+}$ increased from $1.5 \mathrm{~mol} \%$ to $10 \mathrm{~mol} \%$, the intensity of the EPR spectrum has also increased, which is due to the exchange of dipolar interaction of $\mathrm{VO}^{2+}$ [29].

\subsection{Scanning electron microscopy (SEM) analysis}

Scanning electron microscopy (SEM) is often used to study the compatibility between various components of polymer films through the detection of phase separation and interfaces [30, 31]. The compatibility between the polymer matrix and dopants has a great influence on the properties (mechanical, thermal, ionic conductivity) of the polymer films. Also topography study of the samples gives important information regarding the growth mechanism, shape and size of the particles. Scanning electron microscope (SEM) images of pure and $\mathrm{VO}^{2+}$ doped MAA:EA copolymer films are shown in Fig. 8. Fig. 8a clearly shows smooth and uniform surface morphology of the pure MAA:EA copolymer film. This smooth morphology confirms the completely amorphous nature of MAA:EA copolymer. When $\mathrm{VO}^{2+}$ is

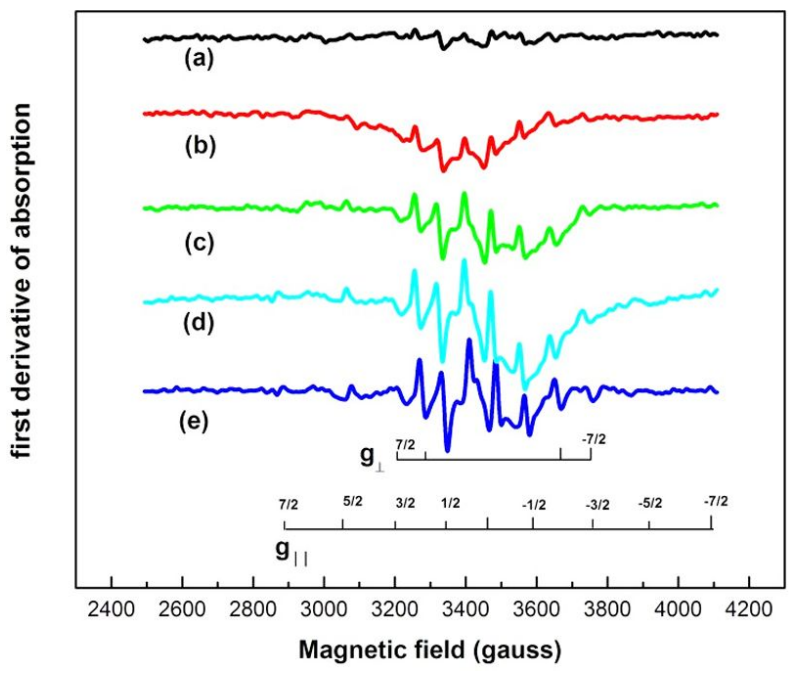

Fig. 7. EPR spectra of MAA:EA copolymer films containing $\mathrm{VO}^{2+}$ (a) $1.5 \mathrm{~mol} \%$, (b) $3.5 \mathrm{~mol} \%$, (c) $5 \mathrm{~mol} \%$, (d) $7.5 \mathrm{~mol} \%$, (e) $10 \mathrm{~mol} \%$.

added to the copolymer, the surface morphology of pure MAA:EA changes from smoother to rougher. Some rumples are also found (Fig. 8b to Fig. 8f). This indicates the semi-crystalline nature of the copolymer caused by the addition of $\mathrm{VO}^{2+}$ ions which is also confirmed by the XRD studies. As the dopant concentration increases, the rumples gradually increase, which may be beneficial for conductivity of the copolymer film [32].

\section{Conclusions}

In summary, it can be concluded that pure and $\mathrm{VO}^{2+}$ doped copolymer films have been successfully synthesized and their structural and optical properties have been analyzed from their XRD, 
Table 2. The anisotropic g factors and the hyperfine structure constants of $\mathrm{VO}^{2+}$ doped MAA:EA copolymer.

\begin{tabular}{ccccc}
\hline $\mathrm{VO}^{2+}$ content $[\mathrm{mol} \%]$ & $\mathrm{g}_{\|}$ & $\mathrm{g}_{\perp}$ & $\begin{array}{c}\mathrm{A}_{\|} \times 10^{-4} \\
{\left[\mathrm{~cm}^{-1}\right]}\end{array}$ & $\begin{array}{c}\mathrm{A}_{\perp} \times 10^{-4} \\
{\left[\mathrm{~cm}^{-1}\right]}\end{array}$ \\
\hline \hline 1.5 & 1.931 & 1.986 & 91 & 43 \\
3.5 & 1.947 & 1.973 & 92 & 43 \\
5 & 1.937 & 1.966 & 90 & 46 \\
7.5 & 1.940 & 1.968 & 92 & 43 \\
10 & 1.942 & 1.963 & 92 & 42 \\
\hline
\end{tabular}

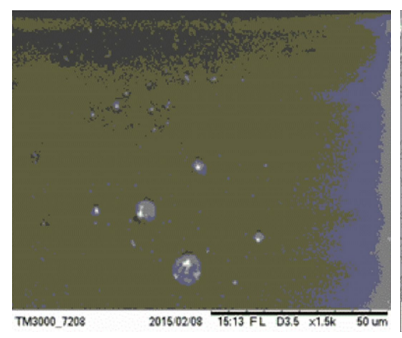

(a)

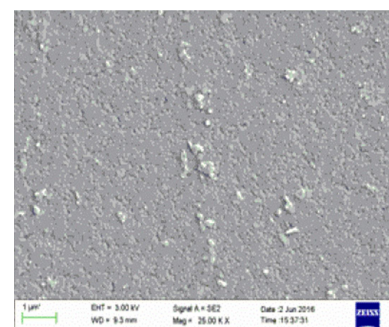

(c)

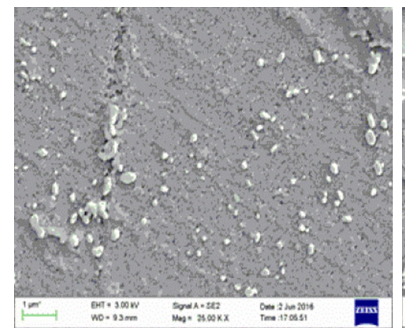

(e)

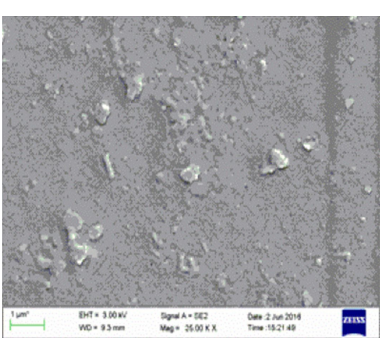

(b)

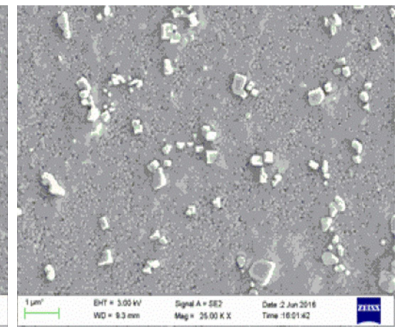

(d)

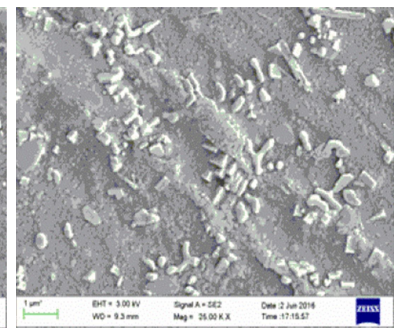

(f)
Fig. 8. SEM photographs of MAA:EA copolymer films containing $\mathrm{VO}^{2+}$ (a) pure, (b) $1.5 \mathrm{~mol} \%$, (c) $3.5 \mathrm{~mol} \%$, (d) $5 \mathrm{~mol} \%$, (e) $7.5 \mathrm{~mol} \%$, (f) $10 \mathrm{~mol} \%$.

FT-IR, UV-Vis, SEM and EPR studies. XRD study revealed the encapsulation of $\mathrm{VO}^{2+}$ by copolymer and some degree of crystallinity. The complexation of the $\mathrm{VO}^{2+}$ with MAA:EA copolymer was confirmed by FT-IR studies. Optical absorption studies showed additional peaks on doping with $\mathrm{VO}^{2+}$ which is characteristic of formation of charge transfer complexes. UV-Vis spectral studies have been carried out to measure the absorption edge and indirect band gap. The band edge and indirect band gap values shifted to lower energies on doping with $\mathrm{VO}^{2+}$ ions which was due to interband transition. The enhanced crystalline nature of the doped copolymer has been identified from SEM analysis. The EPR results showed that $\mathrm{g}_{\|}<\mathrm{g}_{\perp}<\mathrm{g}_{\mathrm{e}}(=2.0023)$ and $\mathrm{A}_{\|}>\mathrm{A}_{\perp}$ for all copolymer samples studied in the present work. Therefore, it has been confirmed that $\mathrm{VO}^{2+}$ exists in the copolymer as $\mathrm{VO}^{2+}$ in octahedral coordination with tetragonal compression.

\section{References}

[1] Leon A.G., Dirix Y., Staedle Y., Feldman K., Hhner G., Caseri W.R., Smith P., Appl. Opt., 39 (2001), 4847.

[2] Srivastava S., Haridas M., Basuj K., Mater. Sci., 31 (2008), 213.

[3] TOKIzAKi T., NAKamura A., Kaneko S., UCHIDA K., OMI S., TANJI H., Asahara Y., Appl. Phys. Lett., 65 (1991), 941.

[4] Wang C., TaM K.C., Jenkins R.D., Tan C.B., J. Phys. Chem. B, 107 (2003), 4667.

[5] WANG C., TAM K.C., TAN C.B., Langmuir, 20 (2004), 7933.

[6] Yoshida K., Dubin P.L., Colloids Surf. A, 147 (1999), 161.

[7] Kosmella S., Kotz J., Shirahama K., LiU J., J. Phys. Chem. B, 102 (1998), 6459.

[8] Cavasino F.P., Hoffmann H., Sbriziolo C., Turco Liver M.L., Colloids Surf. A, 183 (2001), 689.

[9] Bajaj P., Meenakshi G., Chavan R.B., J. Appl. Poly. Sci., 51 (1994), 423.

[10] Warwick M.E.A., Binions R., J. Mater. Chem. A, 2(2014), 3275.

[11] Wang Z., Chen J., Hu X., Thin Solid Films, 375 (2000), 238.

[12] OZER N., Thin Solid Films, 305 (1997), 80.

[13] Livage J., J. Coord. Chem. Rev., 190 - 192 (1999), 391. 
[14] Takahashi K., Wang Y., Cao G., Appl. Phys. Lett., 86 (2005), 053102 (1- 3).

[15] Brydson J.A., Plastic materials, Oxford, North London, 1999.

[16] Zidan H.M., J. Polym. Sci. Pol. Phys., 41 (2003), 112.

[17] Chaudhari H.K., KeKler D.S., J. Appl. Polym. Sci., 62 (1) (1996), 15.

[18] Barbero B.L., Cadus L.E., Appl. Catal. A-Gen., 237 (2003), 263.

[19] Hodge R.M., Edward G.H., Simon G.P., Polymer, 37 (1996), 1371.

[20] Wieczorek W., Stevens J.R., J. Phys. Chem. B., 101 (1997), 1529.

[21] Selim M.S., Seoudi R., Shabaka A.A., Mater. Lett., 59 (2005), 2650.

[22] Madhava Kumar Y., Bhagyasree K., Gopal N.O., Ramu C.H., Adv. Polym. Tech., 6 (2) (2016), 26.

[23] Uma Devi C., Sharma A.K., N Rao V.V.R., Mater. Lett., 56 (2002), 167.

[24] Davis P.W., Shalliday T.S., Phys. Rev., 118 (1960), 1020.
[25] Thutupalli G.M., Tomilin S.G., J. Phys. D. Appl. Phys., 9 (1976), 1639.

[26] RedDeppa N., Sharma A.K., N RAO V.V.R., WEN C., Microelectron. Eng., 112 (2013), 57.

[27] Luan Z., Xu J, He H., Klinowski J., Kevan L., J. Phys. Chem., 100 (1996), 19595.

[28] Abragam A., Bleaney B., Electron Paramagnetic Resonance of Transition Metal Ions, Oxford, Clarendon 1970.

[29] Omkaram I., Sreekanth Chakradhar R.P., Lakshmana Rao J., Physica B, 388(2007), 318.

[30] Zhang S., LeE J Y., Hong L., J. Power Sources, 126 (2004), 125.

[31] Chu P.P., Reddy M.J., J. Power Sources, 115 (2003), 288.

[32] El-Khodary A., Physica B, 405 (2010), 3401.

Received 2017-02-06

Accepted 2018-01-29 